\section{Alexandre Faisal-Cury'}

Paulo Rossi Menezes"

\section{Factors associated with preference for cesarean delivery}

\begin{abstract}
OBJECTIVE: To study factors related to preference for cesarean delivery, among pregnant women without medical complications.
\end{abstract}

METHODS: A cross-sectional study was carried out among 156 pregnant women, in a private clinic in the city of Osasco, State of São Paulo, from October 2000 to December 2001. The pregnant women were at 28 weeks of pregnancy or more, with no formal contraindication for vaginal delivery at the time of the interview. Sociodemographic data and past and present obstetric history were assessed by applying a questionnaire. The pregnant women were specifically asked what their current preference for delivery was. Pearson's Chi-square test and logistic regression for multivariate analysis were performed with a 5\% significance level.

RESULTS: Sixty-seven pregnant women (42.9\%) said they had little motivation to undergo vaginal delivery. In the multivariate analysis, the following variables were statistically significant: previous vaginal birth ( $\mathrm{p}=0.001$; ORadj $=0.04 ; 95 \% \mathrm{CI}=0.01$ 0.12 ); husband's monthly income greater than 750 reais $(p=0.006$, ORadj $=3.44 ; 95 \%$ $\mathrm{CI}=1.38-8.33$ ). The women with a previous vaginal delivery presented 25 -fold lower chance of choosing cesarean delivery. The opinion that the previous delivery experience was unsatisfactory was marginally associated with the main outcome $(p=0.06$; ORadj $=0.42 ; 95 \% \mathrm{CI}=0.16-1.05)$.

CONCLUSIONS: Motivation for cesarean delivery is associated with influences such as the type and degree of satisfaction with previous delivery and income.

KEYWORDS: Delivery obstetrics. Natural childbirth. Patient satisfaction. Health knowledge, attitudes \& practice.
Núcleo de Epidemiologia. Hospital Universitário. Universidade de São Paulo (USP). São Paulo, SP, Brasil

" Departamento de Medicina Preventiva. Faculdade de Medicina. USP. São Paulo, $\mathrm{SP}$, Brasil

\section{Correspondence:}

Alexandre Faisal Cury

Rua Dr. Mário Ferraz, 135/32 Jd Europa

01453-010 São Paulo, SP, Brasil

E-mail: faisal@ip2.com.br 


\section{INTRODUCTION}

The choice of a particular method of birth delivery by the pregnant woman is a modern, complex and controversial subject. "Cesarean by request" has been implicated as one of the causes for the continual increase in cesarean delivery rates. These have been increasing in many countries and have reached $26 \%$ in the United States; $21.3 \%$ in England; $23.9 \%$ in Northern Ireland and 19\% in Canada. ${ }^{12}$ In South America, one ecological study has shown that, in 12 countries that together represent $81 \%$ of deliveries in the region, the levels of cesarean delivery are much above the $15 \%$ recommended by the World Health Organization. In Brazil, over 35\% of deliveries are by cesarean. ${ }^{2}$ Authors from Brazil and other countries have expressed divergent opinions regarding this matter, mostly in relation to the ethical questions. ${ }^{3,22}$ The discussion is generally based upon this progressive increase in the number of cesareans. ${ }^{2}$ For instance, in the United States, there has been a progressive decrease in the levels of vaginal delivery following a previous cesarean, over recent years. ${ }^{17}$ At present, it seems that there is a consensus that the increase in cesarean delivery rates is not only due to medical matters, but is also influenced by psychosocial factors. ${ }^{20}$ This seems to be more evident in developing countries. Several non-medical factors are involved: socioeconomic questions, ethical and legal concerns, and even the psychological and cultural characteristics of the patients and doctors. ${ }^{6}$ The doctor's role as a promoter of an interventionist culture was highlighted in a Brazilian study, ${ }^{13}$ conducted among puerperal women in both private and public clinics. According to this study, three out of four primiparae in the private sector and eight out of 10 in the public sector who had undergone cesarean delivery, wished they had had vaginal delivery. It was observed that the obstetrician stimulated fear among the pregnant women, with regard to the delivery, while overestimating the safety of cesareans, in accordance with their own interests.

There are few reports assessing the real dimensions and importance of "cesarean by request". 8,11 Nor is it not known whether this type of demand varies between countries and cultures. The allegation that many patients prefer the cesarean operation was contested in an important Brazilian prospective study ${ }^{19}$ among 1,136 pregnant women. In this study, 70 to $80 \%$ of the pregnant women from public and private clinics wished to have vaginal delivery. However, this number was much smaller among the women with previous cesareans $(42 \%)$, thus showing that the motivation for vaginal delivery decreases significantly among women who have previously undergone cesarean delivery.
This was even more evident in cases that did not present complications and also in deliveries that the women themselves classified as satisfactory.

The objective of the present work was to study the preference for cesarean or vaginal delivery among pregnant women from a private clinic, and to identify the variables associated with the choice of delivery type.

\section{METHODS}

A cross-sectional study was conducted among 156 pregnant women at a private clinic in the city of Osasco, State of São Paulo, between October 2000 and December 2001. All the pregnant women were seen by a single investigator. The population attended by this clinic essentially consisted of middle-class women living in that city and adjacent municipalities, who had private health plans.

The inclusion criteria adopted were that the women should be at least 28 weeks into their pregnancy, with no formal contra-indication for vaginal delivery (i.e. pelvic presentation, more than one fetus, two or more previous consecutive cesarean operations or other severe clinical conditions). Primiparae were excluded.

A questionnaire was used to obtain sociodemographic information on the woman and her husband (age, ethnic origin, schooling, occupation, income, type of union and length of marriage), and her obstetric history: number of previous pregnancies and parity, number of abortions, number of living children, previous type of delivery (normal, forceps or cesarean), birth weight of last child, requirement for neonatal intensive care unit (ICU) and type of medical assistance used in the last delivery (public or private).

Close to the $28^{\text {th }}$ week (or after this date, in cases where the antenatal assessments were started late), the motivation for vaginal or cesarean delivery was discussed with the patient as an integral part of the obstetric care. On this occasion, the women were invited to participate in this study, and they signed an informed consent declaration prior to answering the questionnaire and the following questions: "Were you satisfied with your last delivery (vaginal or cesarean)?" and "What kind of delivery do you wish to have in this pregnancy?". For the first question, the pregnant woman was asked to classify her answer (satisfaction) as "Yes" or "No". In the second question, she was asked to express her motivation, at that particular moment, towards "vaginal delivery" or "cesarean".

All the explanatory variables were divided into categories. The classification adopted for the variable 
"stress at work" was: 1) domestic work; 2) employee; 3) self-employed or manager. Univariate analysis was performed by means of the Pearson Chi-square test, or the Chi-square test for linear trends, when appropriate. Logistic analysis was used in the multivariate analysis, for which the variables with $\mathrm{p}=0.20$ were considered to be candidates. The statistical significance level was set at $5 \%$.

\section{RESULTS}

The mean age of the pregnant women was 28 years and the monthly average income of the couples was $\mathrm{R} \$ 1,750.00$. No pregnant woman refused to answer the questions posed, possibly because these were pertinent questions for the antenatal follow-up. Most of the women were of white ethnicity $(76.9 \%)$, with schooling up to completed high school level (78.4\%), and a large proportion were working only in domestic activities $(46.1 \%)$, without any personal income $(61.5 \%)$. Around $70 \%$ of them were in their second pregnancy and, out of the group of 156 women, 95 $(60.9 \%)$ and 61 (39.1\%) had had previous cesarean and vaginal delivery, respectively. In total, 67 (42.9\%) of the pregnant women said that they preferred to have cesarean delivery, while the other 89 (57.1\%) wished to try for a vaginal delivery. Concerning the classification of their previous childbirth experience, 39 women classified it as bad while 116 women considered it to have been satisfactory. In this analysis, one woman was indifferent towards her experience and was excluded. Among the "satisfactory" group, 69 (59.5\%) had had cesarean and 47 (40.5\%) had had vaginal delivery. There were no significant differences between the groups regarding the classification of the experience from the previous delivery $(\mathrm{p}=0.61)$.

Table 1 - Characteristics and proportions of pregnant women with preference for cesarean delivery, and the respective odds ratios, 95\% confidence intervals, p-values and order of entry into the multivariate model, for each explanatory variable. Osasco, Brazil, 2000-2001.

\begin{tabular}{|c|c|c|c|c|c|c|}
\hline Variable & Total $(\mathrm{N})$ & Cases $(\%)$ & OR & $95 \% \mathrm{Cl}$ & $\mathrm{p}$ & Order of entry \\
\hline Previous type of delivery & & & & & 0.000 & 1 \\
\hline Cesarean & 95 & $61(64.2)$ & 1 & & & \\
\hline Vaginal & 61 & $6(9.8)$ & 0.06 & $0.01-0.18$ & & \\
\hline Stress & & & & & 0.98 & \\
\hline 1 & 71 & $28(39.4)$ & 1 & & & \\
\hline 2 & 68 & $29(42.6)$ & 1.14 & $0.58-2.27$ & & \\
\hline 3 & 15 & $8(53.3)$ & 1.78 & $0.56-5.55$ & & \\
\hline Ethnicity & & & & & 0.08 & 7 \\
\hline White & 120 & $56(46.6)$ & 1 & & & \\
\hline Brown/Black & 36 & $11(30.5)$ & 0.50 & $0.22-1.13$ & & \\
\hline Pregnant woman's income $(\mathrm{R} \$)$ & & & & & 0.35 & \\
\hline Zero & 96 & $44(45.8)$ & 1 & & & \\
\hline $150-3,000$ & 60 & $23(38.3)$ & 0.73 & $0.38-1.42$ & & \\
\hline Husband's income $(\mathrm{R} \$)$ & & & & & 0.04 & 5 \\
\hline $0-700$ & 43 & $13(30.2)$ & 1 & & & \\
\hline 750-9,900 & 112 & $54(48.2)$ & 2.17 & $1.01-4.76$ & & \\
\hline Couple's income (R\$) & & & & & 0.03 & 2 \\
\hline $0-800$ & 41 & $12(29.2)$ & 1 & & & \\
\hline $850-9,900$ & 115 & $55(47.8)$ & 2.22 & $1.02-5.00$ & & \\
\hline $\begin{array}{l}\text { Pregnant woman's schooling } \\
\text { Elementary/ High School }\end{array}$ & & & & & 0.05 & 4 \\
\hline $\begin{array}{l}\text { Elementary/ High School } \\
\text { University-level }\end{array}$ & 139 & $56(40.2)$ & 1 & & & \\
\hline $\begin{array}{l}\text { University-level } \\
\text { Husband's schooling }\end{array}$ & 17 & $11(64.7)$ & 2.77 & $0.94-8.33$ & & \\
\hline Husband's schooling & & & & & 0.07 & 6 \\
\hline $\begin{array}{l}\text { Elementary/ High School } \\
\text { University-level }\end{array}$ & 120 & $48(40.0)$ & 1 & & & \\
\hline University-level & 33 & $19(57.8)$ & 2.04 & $0.92-4.54$ & & \\
\hline$\underset{2}{\text { Number of pregnancies }}$ & & & & & 0.04 & 3 \\
\hline $\begin{array}{l}2 \\
3-5\end{array}$ & 108 & $52(48.1)$ & 1 & & & \\
\hline $\begin{array}{l}3-5 \\
\text { Miscarriages }\end{array}$ & 48 & $15(31.2)$ & 0.49 & $0.23-1.02$ & & \\
\hline $\begin{array}{l}\text { Miscarriages } \\
0\end{array}$ & & & & & 0.89 & \\
\hline $\begin{array}{l}0 \\
1-3\end{array}$ & 125 & $54(43.2)$ & 1 & & & \\
\hline $\begin{array}{l}1-3 \\
\text { Time since last delivery (vears) }\end{array}$ & 31 & $13(41.9)$ & 0.95 & $0.42-2.12$ & & \\
\hline$\underset{1-2}{\text { Time since last delivery (years) }}$ & & & & & 0.90 & \\
\hline $\begin{array}{l}1-2 \\
3-13\end{array}$ & $\begin{array}{c}38 \\
118\end{array}$ & $\begin{array}{l}16(42.1) \\
51(43.2)\end{array}$ & $\begin{array}{c}1 \\
1.05\end{array}$ & $0.50-2.22$ & & \\
\hline Time when type of delivery was chosen (weeks) & & & & $0.30=2.22$ & 0.09 & 8 \\
\hline 24-34 & 73 & $26(35.6)$ & 1 & & & \\
\hline $35-39$ & 82 & $40(48.7)$ & 1.72 & $0.90-3.33$ & & \\
\hline Did the newborn have to stay in the nursery afte & er the last & delivery (with & subsequent & discharge)? & 0.49 & \\
\hline No & 136 & $57(41.9)$ & 1 & & & \\
\hline Yes & 20 & $10(50.0)$ & 1.38 & $0.54-3.57$ & & \\
\hline Was the previous experience good? & & & & & 0.17 & 9 \\
\hline Yes & 116 & $53(45.6)$ & 1 & & & \\
\hline No & 39 & $13(33.3)$ & 0.72 & $0.78-3.70$ & & \\
\hline Type of hospital (previous delivery) & & & & & 0.30 & \\
\hline $\begin{array}{l}\text { Private } \\
\text { Public }\end{array}$ & 117 & $53(45.3)$ & 1 & & & \\
\hline $\begin{array}{l}\text { Public } \\
\text { Doctor (previous delivery) }\end{array}$ & 39 & $14(35.9)$ & 0.68 & $0.31-1.44$ & & \\
\hline $\begin{array}{l}\text { Doctor (previous delivery) } \\
\text { Private }\end{array}$ & 119 & $54(45.3)$ & 1 & & 0.27 & \\
\hline Public & 37 & $37(35.1)$ & 0.65 & $0.30-1.42$ & & \\
\hline
\end{tabular}


In the univariate analysis, the following variables were shown to be associated with preference for cesarean: previous vaginal delivery $(\mathrm{p}<0.001 ; \mathrm{OR}=0.06 ; 95 \%$ CI: 0.18-0.01), monthly income of the couple over $\mathrm{R} \$ 850.00$ ( $\mathrm{p}=0.03$; OR=2.77; 95\% CI: 1.02-5.0), more than three pregnancies $(\mathrm{p}=0.04 ; \mathrm{OR}=0.49 ; 95 \%$ CI: 0.23-1.02); pregnant women with university degree $(\mathrm{p}=0.05$; OR $=2.04 ; 95 \%$ CI: 0.92-4.54); husband's monthly income over R $\$ 750.00(\mathrm{p}=0.04$; $\mathrm{OR}=2.17$; 95\% CI: 1.01-4.76) (Table 1).

In the multivariate analysis, the following variables were shown to be independently associated: previous type of delivery, in which previous cesarean was associated with preference for cesarean $(\mathrm{p}<0.001$; adjusted $\mathrm{OR}=0.04,95 \%$ CI: 0.01-0.12); and husband's monthly income over $\mathrm{R} \$ 750.00(\mathrm{p}=0.006$; adjusted $\mathrm{OR}=3.44 ; 95 \% \mathrm{CI}: 1.38-8.33$ ). The fact that the pregnant woman did not consider the previous delivery experience to be satisfactory was marginally associated with the outcome $(\mathrm{p}=0.06$; adjusted $\mathrm{OR}=0.42$; 95\% CI: 0.16-1.05) (Table 2).

\section{DISCUSSION}

In this study population of middle-class pregnant women at a private clinic, around $43.0 \%$ said that they preferred to have cesarean delivery by the end of the gestation period. This outcome was strongly associated with the previous type of delivery. Women with previous vaginal delivery presented a much lower chance ( 25 times lower) of choosing a cesarean. On the other hand, women whose husbands had monthly income over R $\$ 750.00$ had a higher chance of choosing a cesarean. Classification of the previous delivery as unsatisfactory was a protective factor for a request for surgical delivery. Women who were not satisfied with the previous delivery had more motivation to try for a vaginal delivery in the present pregnancy.

Before considering the results, some of the limitations of the present study must be highlighted. This was a cross-sectional cohort study, which limits considerations regarding causality. A prospective study would enable assessment of which outcome had occurred, while here the choice was only assessed at a certain point during the antenatal care. Although the study of Potter et al. ${ }^{19}$ showed that there is little change in the numbers of women choosing vaginal delivery over the course of the antenatal assessments, some pregnant women may change their mind regarding the type of delivery, for example, by choosing surgical delivery when they are close to going into labor. The present study was based on only one question to assess the motivation for vaginal delivery (or cesarean). It may be envisaged that some pregnant women do not feel at ease to express what they really want, thinking that it would be socially appropriate to say that they prefer to have vaginal delivery. Likewise, the classification of satisfaction regarding the experience of the previous delivery may be subject to memory flaws (recall bias). Women who considered their experiences negative (unsatisfactory) would be likely to remember the event more clearly. Another factor that could influence this type of recall is the interval between deliveries. The longer the interval is, the higher the risk of a wrong classification of the event would be. The concept of satisfaction itself is too wide to be summarized in one single answer. It is possible that some women liked certain aspects of their delivery care and did not like others, but they judged the degree of importance of these matters according to particular criteria, in order to make an overall evaluation of their previous experience. The results found for these women at a private clinic, who did not present complications, limit their generalization to other populations such as high-risk pregnancies and those attended within the public services. The possibility that women with previous cesareans who were unsatisfied are over-represented in this sample also cannot be ruled out, because of the possibility that the obstetrician involved may not have been performing cesareans systematically, independent of the obstetric indications. However, experiences that were classified as bad (in the previous delivery) and the type of delivery (cesarean and vaginal), shows that there were no significant differences between the groups. Thus, the position of the Obstetrician regarding the question of cesarean requested by the patient does not seem to have influenced the composition of the sample.

Few studies have specifically dealt with the matter of

Table 2 - Estimates from the final logistic regression model, obtained after multivariate analysis. Osasco, Brazil, $2000-2001$.

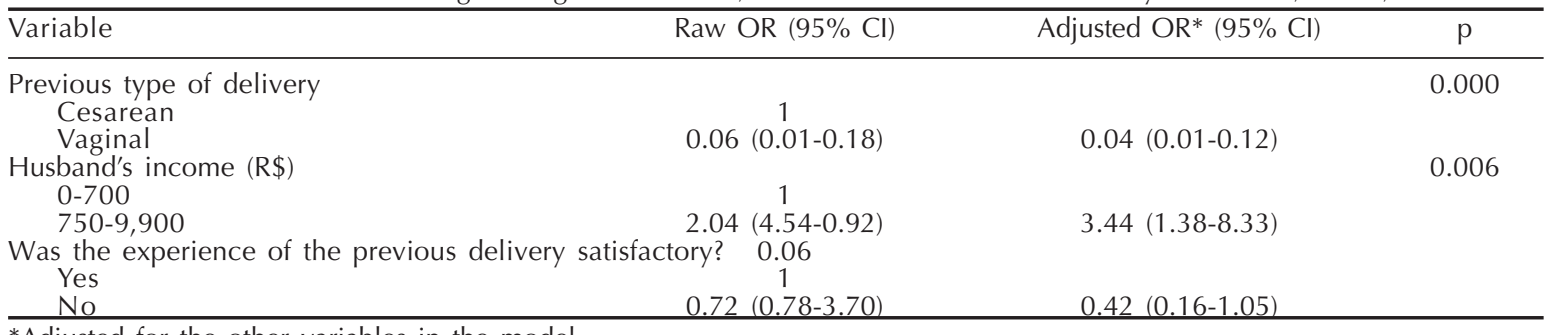

*Adjusted for the other variables in the model 
the preference for cesareans among pregnant women. The real dimension of the problem is not clearly known. It is accepted that a small number of women may choose surgical delivery, but the numbers vary according to the various authors from different countries. One of the most polemical studies on this matter was performed by Al-Mufti \& McCarthy ${ }^{1}$ (1996). These authors sent out an anonymous questionnaire in the post to 282 obstetricians, asking them what kind of delivery they would prefer in their own case (pregnancy of female obstetricians or of male obstetricians' wives), if there were no complications and it was a single fetus in the cephalic presentation, at full term. Around $8 \%$ of the men and $31 \%$ of the women chose cesarean delivery. A cross-sectional study among 160 Asian pregnant women showed that 3.7\% of them wanted to undergo planned cesarean. ${ }^{4} \mathrm{~A}$ study performed in Belgium found that at least $2.6 \%$ of pregnant women planned to have surgical delivery. ${ }^{14}$

In Italy, an interview carried out no later than the fifth day after delivery showed that $9 \%$ of the women with vaginal delivery and $27 \%$ of the women with a previous cesarean would have preferred vaginal delivery. ${ }^{7}$ Obviously, studies performed during the puerperal period do not allow adequate assessment of the women's motivation during their pregnancy and are subject to influence from the delivery method that was actually used.

Some studies, however, have approached the question prospectively. In Sweden, a postal survey covering more than 3,000 women showed that only $8 \%$ of the women would have preferred a cesarean delivery. ${ }^{13}$ In Australia, a study assessed 310 women between their $36^{\text {th }}$ and $40^{\text {th }}$ weeks of pregnancy, noting $93 \%$ preference for vaginal delivery. ${ }^{8}$ In the largest national study, Potter et al ${ }^{19}$ prospectively followed 1,136 women during antenatal consultations, finding that 20 to $30 \%$ of them preferred cesareans. However, for the women with previous cesareans, only around $58 \%$ had wanted a cesarean.

In the present study, $43 \%$ of the women said that they lacked motivation to try vaginal delivery and expressed a desire to undergo cesarean. When the choice of cesarean was analyzed according to previous delivery, it was observed that $64.2 \%$ of the pregnant women with previous cesareans preferred to repeat the procedure, versus only $9.8 \%$ of the pregnant women with previous vaginal delivery. Indeed, previous cesarean is an important factor in the choice of subsequent delivery. The repetition of cesareans has been shown to be the main factor in maintaining the cesarean rates in developed countries, concomitantly with the decline in attempts at vaginal delivery fol- lowing a cesarean. ${ }^{17}$

Other factors associated with preference for cesareans that were also observed included cases of greater numbers of pregnancies, the socioeconomic level of the couple, and the degree of satisfaction with the experience from the previous delivery.

Women with more than three pregnancies presented a lower chance of having a lack of motivation for vaginal delivery. In the univariate analysis, they presented $50 \%$ less chance of asking for a cesarean. One possible explanation lies in the fact that these women had satisfactory previous vaginal deliveries. The study excluded women with more than one consecutive previous cesarean, but did not limit the number of women with previous vaginal deliveries. It is possible that multiparous women with previous vaginal deliveries are better motivated to try vaginal delivery again. Nulliparity, on the other hand, has been associated with higher risk of cesarean. ${ }^{16}$

Regarding socioeconomic level, as assessed by the husband's income, it was shown that the higher the income was, the lower the motivation for normal delivery was. In the final logistic model, women whose husbands had higher income had a higher chance of choosing a cesarean. This had already been noticed in the univariate analysis, in relation to the variable of the couple's income, which in this sample was determined basically by the men's income. Likewise, the variables of the pregnant woman's schooling $(p=0.05)$ and husband's schooling $(p=0.07)$, which were related to socioeconomic level, presented an association with choosing a cesarean. This association between higher socioeconomic level and cesareans has been observed by many authors. In Chile, a retrospective study ${ }^{18}$ among 540 puerperal women observed that those with private care available, i.e. those of higher socioeconomic level, had a higher chance of undergoing cesarean than those attended in public clinics. The possible explanations for this include the kind of medical care and hospital services, as well as the way in which the woman participates in the decision-making process regarding the type of delivery. ${ }^{10}$ However, in the present study, the univariate analysis did not show an association between motivation for cesarean and use of a private hospital (or private doctor) for the previous delivery. The small size of the group of patients coming from public units $(37 / 156)$ may have created difficulties in finding such an association.

Negative experience from the previous delivery was a protective factor for the lack of motivation for vaginal delivery. In the final logistic model, women with 
negative experience had around $60 \%$ higher chance of being motivated to try normal delivery. It can be imagined that these pregnant women, through discontent with the previous delivery, see normal delivery as a better or safer alternative.

Some authors have dealt with the question of the influence of previous experience on the choice of delivery method. A study ${ }^{21}$ including 1,050 puerperal women showed that the woman's satisfaction level, even though generally very high, is higher in elective cesarean than it is in vaginal delivery. However, it is significantly lower in emergency cesarean and in vaginal deliveries using a vacuum extractor. A high level of satisfaction with cesareans was found in a crosssectional study ${ }^{7}$ performed no later than the fourth day after delivery, among 166 women who underwent cesarean. Nonetheless, the subject is not free from controversy, since other studies have shown the same results among women who had normal deliveries. What can be seen from these studies is that, independent of the type of delivery, the woman's discontent is related to the adverse maternal results and particularly with regard to the newborn. According to some authors, previous negative experience is an important factor in requesting cesareans. ${ }^{23}$ It is also worth highlighting the subjective dimension of each and every experience, including pregnancy and delivery. Satisfaction is a concept that is difficult to measure and interpret, and is often closely related to the type of antenatal care received and the neonatal outcome.

While there are still many doubts regarding the motivations for vaginal delivery, some authors have also sought to study obstetricians' acceptance of requests from women for cesareans. The numbers vary according to authors from different countries: $45 \%$ in Israel, ${ }^{9} 69 \%$ in England, ${ }^{5}$ and 30\% in Belgium. ${ }^{14}$ There are no national studies assessing the attitude of Brazilian obstetricians towards cesarean by request.

Finally, it is worth highlighting that the question of cesarean by request is not only a problem of medical concern, since it is incorporated within complex social contexts ${ }^{15}$ that deserve to be researched. Qualitative studies designed to assess the preferences of the patient and the doctor for cesareans, and their complex interactions are essential and urgent. Such studies may provide the basis for effective and safe obstetric interventions that aim to reduce cesarean rates.

\section{REFERENCES}

1. Al-Mufti R, McCarthy A, Fisk NM. Obstetricians' personal choice and mode of delivery. Lancet. 1996;347(9000):544-5.

2. Belizan JM, Althabe F, Barros FC, Alexander S. Rates and implications of cesarean sections in Latin America: ecological study. BMJ.

1999;319(7222):1397-400.

3. Camano L, Souza E, Santos JFK, Sass N, Mattar R, Guaré SO. Segunda opinião para indicação de cesariana. Femina. 2001;29(6):345-50.

4. Chong ES, Mongelli M. Attitudes of singapore women toward caesarean and vaginal deliveries. Int J Gynaecol Obstet. 2003;80(2):189-94.

5. Cotzias CS, Paterson-Brown S, Fisk NM. Obstetricians say yes to maternal request for elective cesarean section: a survey of current opinion. Eur J Obstet Gynecol Reprod Biol. 2001;97(1):15-6.

6. Cury AF, Tedesco JJA. Aspectos polêmicos na indicação da cesareana. Femina. 2003;31(9):809-12.

7. Donati S, Grandolfo ME, Andreozzi S. Do italian mothers prefer cesarean delivery? Birth. 2003;30(2):89-93.
8. Gamble JA, Creedy DK. Women's request for cesarean section: a critique of the literature. Birth. 2000;27(4):256-63.

9. Gonen R, Tamir A, Degani S. Obstetricians' opinions regarding patient choice in cesarean delivery. Obstet Gynecol. 2002;99(4):577-80.

10. Gould JB, Davey B, Stafford RS. Socioeconomic differences in rates of cesarean section. N Engl J Med. 1989;321(4):233-9.

11. Graham WJ, Hundley V, McCheyne AL, Hall MH, Gurney E, Milne J. An investigation of women's involvement in the decision to delivery by cesarean section. Brit J Obstet Gynaecol. 1999;106(3):213-20.

12. Guise JM, Hashima J, Osterweil P. Evidence-based vaginal birth after caesarean section. Best Pract Res Clin Obstet Gynaecol. 2005;19(1):117-30.

13. Hopkins K. Are brazilian women really choosing to delivery by cesarean? Soc Sci Med. 2000;51(5):725-40.

14. Jacquemyn Y, Ahankour F, Martens G. Flemish obstetricians' personal preference regarding mode of delivery and attitude towards caesarean section on demand. Eur J Obstet Gynecol Reprod Biol. 2003;111(2):164-6. 
15. Kirk EP, Doyle KA, Leigh J, Garrard ML. Vaginal birth after cesarean or repeat cesarean section: medical risks or social realities? Am J Obstet Gynecol. 1990;162(6):1398-403.

16. Luthy DA, Malmgren JA, Zingheim RW, Leininger CJ. Physician contribution to a cesarean delivery risk model. Am J Obstet Gynecol. 2003;188(6):1579-87.

17. Martin JA, Hamilton BE, Ventura SJ, Menacker F, Park MM, Sutton PD. Births: final data for 2001. Natl Vital Stat Repr. 2002;51(2):1-103.

18. Murray SF. Relation between private health insurance and high rates of cesarean section in Chile: qualitative and quantitative study. BMJ. 2000;321(7275):1501-5.
19. Potter JE, Berquó E, Perpétuo IGHO, Leal OF, Hopkins K, Souza MR, et al. Unwanted cesarean sections among public and private patients in Brazil: prospective study. BMJ. 2001;323(7322):1155-8.

20. Sachs BP, Kobelin C, Castro MA, Frigoletto F. The risk of lowering the cesarean-delivery rate. $N$ Engl J Med. 1999;340(1):54-7.

21. Schindl $M$, Birner $P$, Reingrabner $M$, Joura EA, Husslein $P$, Langer $M$. Elective cesarean section vs spontaneous delivery: a comparative study of birth experience. Acta Obstet Gynecol Scand. 2003;82(9):834-40.

22. Scott JR. Putting elective cesarean into perspective. Obstet Gynecol. 2002;99(6):967-8.

23. Turnbull DA, Wilkinson C, Yaser A, Carty V, Svigos JM, Robinson JS. Women's role and satisfaction in the decision to have a caesarean section. Med J Aust. 1999;170(12):580-3. 